\title{
Comentarios al procedimiento de control de concentraciones en el sector eléctrico peruano
}

\author{
Alejandro Manayalle Chirinos* \\ Francisco José Floríndez Aramburú**
}

Resumen. - En el presente artículo, los autores contemplan la necesidad de implementar un mecanismo de control de fusiones para el sector eléctrico. Como punto de partida, se observa el contexto previo a la promulgación de las normas relacionadas con el actual. A partir de esto, los autores realizan un análisis para determinar si aún debe haber control de concentraciones en este sector.

\begin{abstract}
In the following article, the authors contemplate the need to implement a merger control mechanism for the electric sector. As a starting point, it observes the context prior and later to the promulgation of certain laws. With this comparison, the authors perform an analysis to determine if they should still have a concentration control in this sector.
\end{abstract}

Palabras claves. - Control de procedimientos - Sector eléctrico - INDECOPI Autorización previa - Ley antimonopolio.

Keywords. - Procedure control - Electrical Sector - INDECOPI - Prior authorization - Anti-Monopoly Law.

* Abogado por la Pontificia Universidad Católica del Perú y L.L.M por Columbia University. Profesor de Derecho de Energía y Minería en la Pontificia Universidad Católica del Perú. Socio del área de Regulación de Servicios Públicos de Rodrigo, Elías \& Medrano Abogados. Contacto: amanayalle@estudiorodrigo.com

** Bachiller en derecho por la Pontificia Universidad Católica del Perú. Asociado del área de Regulación de Servicios Públicos de Rodrigo, Elías \& Medrano Abogados. Contacto: fflorindez@estudiorodrigo.com 


\section{Introducción}

A raíz de los recientes debates y de la aprobación de una norma (que no ha sido aún publicada) sobre la necesidad de implementar un mecanismo de control de fusiones para todas las industrias en el Perú, resulta importante revisar las características del único instituto jurídico que regula dicho supuesto en el país.

En el Perú, el único sector cuyas operaciones están sujetas a un control previo de concentraciones es el sector eléctrico, que comprende las actividades de generación, transmisión y distribución. Ello es así desde la promulgación de la Ley 26876, Ley Antimonopolio y Antioligopolio del Sector Eléctrico ("LASE"), que fue posteriormente reglamentada por el Decreto Supremo 017-98-ITINCI ("RLASE").

En el presente artículo se analizará cómo se ha aplicado el referido mecanismo de control en sus más de veinte años de vigencia, a la luz de los pronunciamientos emitidos por el Instituto Nacional de Defensa de la Competencia y de la Protección de la Propiedad Intelectual (“INDECOPI”).

Para ello, es importante analizar el contexto en el que se emitieron las normas antes señaladas, y el escenario en el que nos encontramos el día de hoy. En el pasado, la mayoría de empresas del sector eléctrico estaban en manos del Estado, y la competencia en el mercado era reducida o incluso inexistente. Consecuentemente, la seguridad enérgica del país podía verse comprometida por la decisión de un solo agente económico.

En ese contexto, se establece el control de concentraciones en el sector eléctrico con el objetivo de que dichas actividades recaigan en actores diferentes y que, con ello, se alcance una mayor seguridad energética.

Sin perjuicio de lo anterior, es evidente que, hoy en día, las características del sector eléctrico no son las mismas que hace veinte años. A diferencia de lo señalado anteriormente, hoy en día nos encontramos frente a un sector que cuenta con diversos agentes económicos y, por tanto, en una situación de mayor seguridad energética.

Teniendo en cuenta lo anterior, conviene preguntarse si es que sigue siendo necesario contar con un control de concentraciones en el sector eléctrico.

\section{Procedimiento de autorización previa a cargo del INDECOPI}

Como adelantamos en la sección precedente, el sector eléctrico es el único que se encuentra sujeto a un control previo de concentraciones en el Perú. En concreto, el artículo 3 de la LASE establece que los actos de concentración en las actividades de generación, transmisión y/o distribución de energía eléctrica deben ser previamente autorizados por la Comisión de Libre Competencia del INDECOPI ("CLC"). Pero, ¿cuál es el objetivo de un control de concentraciones?

$\mathrm{Al}$ respecto, la doctrina indica que:

“en términos estrictamente técnicos, el control de operaciones de 
concentración es un instrumento de la política de competencia que busca prevenir futuras restricciones a la competencia. Se trata de un instrumento de intervención ex ante con un objetivo económico basado en el control de estructuras, esto es, en evitar que se generen estructuras de mercado proclives a comportamientos anticompetitivos"1.

A partir de lo anterior, queda claro que el control de concentraciones es un instrumento destinado a promover y proteger la competencia en un mercado determinado, al prevenir que un solo agente económico ostente una posición monopólica o dominante. Como es lógico, un agente económico que cuente con una posición monopólica o dominante tendrá mayor facilidad para realizar comportamientos anticompetitivos (por ejemplo, concertaciones, negativa injustificada de trato, fijación de precios predatorios, entre otros).

Debido a la importancia de la energía en el desarrollo económico del país, la implementación del mecanismo de control previo de concentraciones en el sector eléctrico tuvo como objetivo principal dotar al Perú de una mayor seguridad energética, al reducir la posibilidad de que los agentes económicos que participan en el referido mercado realicen prácticas anticompetitivas. En líneas generales, el régimen de control previo de concentraciones buscó evitar que un solo agente económico (o un número reducido de agentes económicos) tenga control sobre un sector tan estratégico como el sector eléctrico.

Ahora bien, a continuación se analizarán los aspectos puntuales del referido mecanismo de control.

\section{i. Acto de concentración}

La A efectos de comprender el régimen de control previo de concentraciones en el sector eléctrico resulta necesario entender, en primer lugar, qué constituye un acto de concentración.

Al respecto, el artículo 2 de la LASE señala lo siguiente:

"Para los efectos de la presente Ley, se entiende por concentración la realización de los siguientes actos: la fusión; la constitución de una empresa en común; la adquisición directa o indirecta del control sobre otras empresas a través de la adquisición de acciones, participaciones, o a través de cualquier otro contrato o figura jurídica que confiera el control directo o indirecto de una empresa incluyendo la celebración de contratos de asociación "joint venture", asociación en participación, uso o usufructo de acciones y/o participaciones, contratos de gerencia, de gestión, y de sindicación de acciones o cualquier otro contrato de colaboración empresarial similar, análogo y/o parecido y de consecuencias similares. Asimismo, la adquisición de activos productivos de cualquier empresa que desarrolle actividades en el sector; o cualquier otro acto, contrato o figura jurídica incluyendo legados, por virtud del cual se concentren sociedades, asociaciones, acciones, partes sociales, fideicomisos o activos en general, que se realice entre competidores, proveedores, clientes, accionistas $\mathrm{o}$ cualesquiera otros agentes económicos"

1 ROLDÁN BARRAZA, Nicole. Control de Fusiones: evaluando la conveniencia de su aplicación en Perú. RAE Jurisprudencia. Lima: diciembre 2012. P.44. 
A partir de lo anterior, es posible identificar dos tipos de "actos de concentración": (a) los actos que confieren a un agente económico el control directo o indirecto sobre una empresa eléctrica; y, (b) los actos que involucran la adquisición de activos productivos de titularidad de empresas pertenecientes al sector eléctrico.

A continuación, se analizarán ambos supuestos:

a. Actos que confieren control directo o indirecto sobre una empresa eléctrica:

Con relación a este tipo de "acto de concentración", la CLC ha indicado que estos son "(...) entre otros, aquellos que tengan como efecto una modificación permanente de la estructura de control de las empresas participantes (...)"2. Así, en este caso el término "concentración" está íntimamente vinculado al control ${ }^{3}$ que tiene un agente económico sobre una empresa determinada.

A partir de lo anterior, no se considerarán actos de concentración aquellas operaciones que no tengan mayor incidencia en la estructura de control de una empresa eléctrica; esto es, que el poder de decisión de la empresa no se vea alterado por la operación.

Esto último es fácilmente apreciable en la Resolución 082-2009/CLC, mediante la cual la CLC declaró improcedente la solicitud de autorización previa presentada por Electro Sur Este S.A.A. para la adquisición de la Central Hidroeléctrica Hercca de propiedad de la Empresa de Generación Eléctrica Machupicchu S.A. En dicha oportunidad, la CLC señaló que ambas empresas eran controladas por el Estado y que, por tanto, no se producía variación alguna en la estructura de control ${ }^{4}$.

Del mismo modo, tampoco se considerarán como actos de concentración las operaciones realizadas por empresas que -a la fecha de la operación- no participen en el mercado eléctrico peruano.

A efectos de analizar este tipo de acto de concentración, es imprescindible mencionar que la LASE se refiere a dos clases de control: directo e indirecto. Por un lado, deberá entenderse que un agente cuenta con control directo sobre una empresa cuando "(...) ejerce más de la mitad del poder de voto en la junta general de accionistas $(\ldots)^{\prime \prime} 5$.

Por otro lado, el control indirecto ocurrirá cuando el agente económico que adquiera acciones de una empresa cuente con la “(..) facultad para designar, remover o vetar a la mayoría de los miembros del directorio u órgano equivalente, para ejercer la mayoría de los votos en las sesiones del directorio u órgano equivalente, o para gobernar las políticas operativas y/o financieras; aun cuando no ejerce más de la mitad del poder de voto en la junta general de accionistas y

Resolución 001-2010/CLC-INDECOPI, Fundamento 14.

La CLC ha definido el concepto de "control" como la influencia "(...) preponderante y continua en la adopción de las decisiones estratégicas de los órganos de gobierno de una persona jurídica. A su vez, las decisiones relevantes (...) son aquellas que definen la estrategia competitiva de la empresa (...)". Ver Resolución No 034-2014/CLC-INDECOPI, Fundamento 39.

4 Resolución 082-2009/CLC-INDECOPI, Fundamento 22.

5 Resolución 082-2009/CLC-INDECOPI, Fundamento 16. 
tomar decisiones estratégicas, aún sin ejercer la mayoría del poder de voto" 6 . En ambos supuestos, las operaciones realizadas podrían ser, en principio, revisadas por el INDECOPI.

Del mismo modo, el control directo o indirecto podrá ocurrir de manera exclusiva o conjunta. Así, un agente económico tendrá control exclusivo cuando pueda determinar la estrategia competitiva de una empresa sin que exista contrapeso $u$ oposición. Por el contrario, existirá control conjunto cuando dos o más agentes económicos tengan el poder para tomar decisiones dentro de una misma empresa, por lo que dichos agentes deberán adoptar acuerdos para ejercer el control de la empresa de manera efectiva 7 .

b. Actos que involucran la adquisición de activos productivos de titularidad de empresas pertenecientes al sector eléctrico.

Por otro lado, este tipo de acto de concentración se refiere a la adquisición por parte de una empresa del sector eléctrico de activos productivos pertenecientes a otra empresa del sector. Sobre el particular, la CLC ha señalado que la transferencia de activos productivos constituye en sí mismo un acto de concentración, ello sin importar el grado de utilización ${ }^{8}$.

En atención a lo anterior, no serán considerados como actos de concentración la adquisición de activos no productivos ${ }^{9}$, la ejecución de proyectos greenfield ${ }^{10} \mathrm{ni}$ la adquisición de activos productivos por parte de una empresa que -a la fecha de la operación- no participe en el sector eléctrico.

Como se puede apreciar, ambos tipos de actos de concentración requieren necesariamente de la participación de al menos dos empresas que desarrollen sus actividades en el sector eléctrico. Al respecto, el literal f) del artículo 2 del RLASE considera como empresas que desarrollan sus actividades en el sector eléctrico a aquellas que cuenten con autorizaciones y/o concesiones para desarrollar actividades eléctricas.

Adicionalmente, en el marco de los procesos de promoción de la inversión privada a cargo de la Agencia de Promoción de la Inversión Privada ("PROINVERSIÓN"), serán consideradas como empresas que desarrollan actividades en el sector eléctrico aquellas que, además de contar con una autorización y/o concesión

\footnotetext{
Resolución 082-2009/CLC-INDECOPI, Fundamento 16.

Resolución 034-2014/CLC-INDECOPI, Fundamentos 40-46.

Resolución 007-2014/CLC-INDECOPI, Fundamento 22.

9 De conformidad con el artículo $10^{\circ}$ del RLASE, "Se considerarán como activos productivos aquellos bienes que a la fecha de realización de la operación se encuentren bajo el control de las Empresas que Desarrollan Actividades, ya sea porque son de su propiedad o debido a cualquier acto, contrato o figura jurídica que así lo permita. La adquisición de activos productivos sólo se encuentra sujeta al procedimiento de autorización previa si los mismos permiten mediante su adquisición incrementar la participación de la empresa o grupo que los adquiere en el desarrollo de Actividades, considerándose el valor de mercado de los mismos en la fecha en que se realice la Notificación".

10 Los proyectos greenfield son aquellos que se desarrollan desde cero, esto es, aquellos proyectos que aún no han sido ejecutados.
} 
eléctrica cuenten con activos productivos (artículo 2 del Decreto Supremo 0872002-EF).

Finalmente, de conformidad con el artículo 9 de la LASE, también se considerarán como actos de concentración -sujetos al control previo del INDECOPI- aquellas operaciones realizadas en el extranjero que involucren directa o indirectamente a empresas que operan en el sector eléctrico nacional. En otras palabras, estarán sujetas al control de INDECOPI aquellas operaciones realizadas en el extranjero que tengan efectos en el mercado eléctrico peruano ${ }^{11}$.

\section{ii. Supuestos que no requieren de la autorización previa de la CLC}

Habiendo explicado qué constituye un acto de concentración, cabe indicar que no todos los referidos actos requieren de la autorización previa de la CLC. Así, teniendo en cuenta los umbrales establecidos en el artículo 3 de la LASE, los siguientes actos de concentración no estarán sujetos al referido mecanismo de control:

1) Actos de concentración horizontal que involucren a empresas que poseen de manera conjunta o separada menos del 15\% del mercado en el que actúan: En este supuesto están comprendidos los actos de concentración dentro del mismo eslabón de la cadena productiva; esto es, dos o más empresas de generación; dos o más empresas de transmisión; o, dos o más empresas de distribución.

De conformidad con el artículo 3 de las LASE, la participación en el mercado de las empresas eléctricas que intervienen en la operación de concentración deberá ser analizada antes y después de que esta sea realizada. Así, no estarán comprendidas dentro de ésta excepción (y, por tanto, deberán solicitar la autorización del INDECOPI) aquellos actos de concentración que involucren a empresas que, de manera conjunta o separada, ostenten $15 \%$ o más del mercado (antes o después de la operación).

2) Actos de concentración vertical que involucren a empresas que posean menos del 5\% en cualquiera de los mercados involucrados: A diferencia del supuesto anterior, esta excepción aplica únicamente para aquellos actos de concentración que operan en planos distintos de la cadena productiva (por ejemplo, operación realizada por una empresa de generación y una empresa de transmisión).

11 Con relación a este supuesto, la CLC indica que "En efecto, sin importar el lugar donde se realice el acto de concentración, su consumación origina el efecto inmediato de modificar la estructura de control de las empresas involucradas, y de todas aquellas empresas sobre las que éstas ejercen control directo o indirecto. La modificación de la estructura de control otorga, a favor de la empresa que lo adquiere, la potestad de decidir sobre las actividades de las empresas involucradas, situación que se puede manifestar realizando o no realizando cambios en la organización o el funcionamiento de dichas empresas". Ver Resolución 001-2010/CLCINDECOPI, Fundamentos 41-45. 
En este caso, no será necesario obtener la aprobación del INDECOPI si el acto de concentración involucra a empresas que posean -antes o después de realizada la operación- menos del $5 \%$ de los mercados involucrados.

3) Actos de concentración que importen la adquisición de activos productivos que representen menos del 5\% del valor total de los activos productivos de la empresa adquirente: A diferencia de las excepciones mencionadas en los puntos precedentes, en este caso solo se analiza el impacto del acto de concentración en la esfera de la empresa adquirente.

Así, no requerirán de la autorización previa del INDECOPI aquellos actos de concentración que involucren la compra de activos productivos que importen menos del $5 \%$ de los activos productivos de la empresa adquirente.

4) La acumulación de menos del $10 \%$ del total de las acciones o participaciones con derecho a voto de una empresa eléctrica: Según lo previsto en la LASE, no requerirán de la autorización previa del INDECOPI aquellos actos de concentración que involucren la acumulación directa o indirecta por parte de un mismo agente económico de menos del 10\% del total de las acciones o participaciones con derecho a voto de una empresa eléctrica.

Al respecto, es importante destacar la utilización del término "acumulación" en el literal b) del artículo 3 de la LASE. Lo anterior implica que basta que el acto de concentración conlleve a que un mismo agente económico ostente $10 \%$ o más de las acciones o participaciones con derecho a voto de la empresa adquirida para que la operación requiera de la autorización previa del INDECOPI; ello sin importar la cantidad de acciones o participaciones con derecho a voto efectivamente adquiridas en la operación (en otras palabras, la operación podría comprender la venta de menos del 10\% de las acciones o participaciones de la empresa adquirida pero aún así estar sujeta a la autorización previa del INDECOPI).

Finalmente, la norma es clara al señalar que "se requerirá necesariamente de autorización si el acto de concentración permite adquirir el control directo o indirecto de la empresa que desarrolla alguna de las actividades eléctricas mencionadas $(. . .)^{\prime \prime}$. Como se puede apreciar, la excepción tiene por objeto que solo las operaciones que impliquen un cambio efectivo en la estructura de control de la empresa adquirida requieran de la autorización previa del INDECOPI, con la finalidad de no alterar el dinamismo del mercado.

En ese orden de ideas, es posible sostener que aquellas empresas adquirentes que ostenten el control de la empresa adquirida antes de la realización del acto de concentración no deberían requerir la autorización previa del INDECOPI, toda vez que la estructura de control de esta última no se vería alterada. 
Los umbrales a los que se refieren los numerales 1) y 2) antes mencionados son de particular importancia, toda vez que excederlos generará la obligación de obtener la autorización previa del INDECOPI antes de realizar la operación de concentración.

$\mathrm{Al}$ respecto, el artículo 8 del RLASE señala lo siguiente:

“Deberá solicitarse la autorización previa respecto de las Operaciones de Concentración que involucren, directa o indirectamente, a Empresas que Desarrollan las Actividades que posean previa o posteriormente al acto que originó la solicitud de autorización, de manera conjunta o separada, un porcentaje igual o mayor al 15\% del mercado en los actos de concentración horizontal. En el caso de actos de concentración vertical, aquéllos que involucren, directa o indirectamente, a Empresas que Desarrollan las Actividades que posean previa o posteriormente al acto que originó la solicitud de autorización, un porcentaje igual o mayor al 5\% de cualquiera de los mercados involucrados".

En atención a lo anterior, los agentes económicos que participen en un operación con incidencia en el sector eléctrico deberán analizar los siguientes factores para determinar si deben o no solicitar la autorización previa al INDECOPI: (i) definir si la operación constituye un "acto de concentración; y, (ii) verificar si la operación excede los umbrales establecidos en el segundo párrafo del artículo $3^{\circ}$ de la LASE. Solo aquellas operaciones que cumplan con las características antes mencionadas requerirán de la autorización previa del INDECOPI.

Finalmente, cabe señalar que los umbrales antes mencionados son cuestionables, toda vez que estos carecen de sustento técnico. Por el contrario, los referidos umbrales parecen responder a una decisión legislativa que nada tiene que ver con el efecto que este tipo de operaciones pueda tener en el mercado.

$\mathrm{Al}$ respecto, Sergio Salinas refiere que

“(...) Ni el Ministerio de Energía y Minas, ni el Organismo Supervisor de la Inversión en Energía -OSINERG-, ni el Indecopi han justificado estos porcentajes en documento alguno. En realidad, parece que el objetivo buscado es evitar la reducción del número de operadores en el mercado, o lo que es lo mismo, forzar -inútilmente, vale la pena añadir- la existencia de un número mínimo de estos"12.

\section{iii. Etapas del procedimiento de autorización previa}

El procedimiento de autorización previa a cargo del INDECOPI consta de las siguientes etapas:

a. Notificación: Existe una obligación de notificar a la CLC la realización de aquellos actos de concentración que sobrepasen los umbrales establecidos en el segundo párrafo del artículo 3 de la LASE.

12 SALINAS RIVAS, Sergio. La Ley antimonopolio en el sector eléctrico ¿sobreregulando el mercado? En: Ius et Veritas. No 33. P. 157. 
De conformidad con el artículo 13 del RLASE, la operación deberá ser notificada: (i) por las empresas que participan en la operación, tratándose de casos de fusión, conformación de empresas en conjunto o de toma de control conjunto; y, (ii) por el adquirente, cuando se trate de una adquisición de la totalidad o parte de una empresa eléctrica.

La notificación deberá incluir como mínimo los siguientes documentos:

- Identificación de los administrados que presentan la notificación y de las partes que intervienen en la operación;

- Descripción de la estructura de propiedad y de control de los agentes económicos que intervienen en la operación de concentración;

- Descripción de los vínculos entre las partes que participan en la operación y otras empresas que desarrollan sus actividades en el mercado analizado o en mercados relacionados;

- Descripción de la operación y relación de los mercados afectados;

- Información sobre los mercados afectados por la operación;

- Descripción de los efectos de la operación en el mercado, así como también sobre las eficiencias económicas generadas; $y$,

- Copia de los documentos más recientes relativos al cierre de la operación y de los estudios o análisis realizados por las empresas que participan en la operación, a efectos de analizar el impacto del acto de concentración en la competencia, los competidores y la situación del mercado.

- Cabe señalar que la CLC se encuentra facultada para requerir la presentación de información adicional que resulte necesaria para realizar su análisis. Asimismo, nótese que la información contenida en la notificación tendrá carácter de declaración jurada.

b. Verificación: La Secretaría Técnica de la CLC tendrá un plazo de cinco (5) días desde la presentación de la solicitud para determinar si la información presentada por los administrados se encuentra completa. En caso la información se encuentre incompleta, la Secretaría Técnica otorgará a los administrados un plazo de cinco (5) días para subsanar la solicitud; caso contrario, esta se entenderá como no presentada.

c. Requerimiento de información adicional: Una vez que la solicitud esté completa o luego de vencidos los plazos mencionados en el numeral anterior, la CLC o la Secretaría Técnica dispondrá de un plazo de diez (10) días para solicitar datos o documentos adicionales que sean necesarios para la evaluación del acto de concentración. La información adicional solicitada por la CLC o por la Secretaría Técnica deberá ser presentada en un plazo máximo de diez (10) días. 
d. Decisión: La CLC dispondrá de un plazo de treinta (30) días para evaluar la operación. Asimismo, la Secretaría Técnica deberá presentar a la CLC su opinión acerca de la operación dentro los primeros veinte (20) días del plazo antes mencionado, incluyendo su análisis sobre los efectos de la operación en el mercado, su recomendación sobres medidas para garantizar la compatibilidad de la operación con el mercado y su recomendación sobre las sanciones que se deben imponer, de ser el caso. El plazo de treinta (30) días antes mencionado podrá ser ampliado en caso la CLC requiera profundizar en el análisis.

Según lo previsto en el artículo 24 del RLASE, la CLC podrá adoptar cualquiera de las siguientes decisiones: (i) declarar improcedente la solicitud por considerar que la operación no se encuentra dentro del ámbito de aplicación de la LASE; (ii) autorizar la operación, en la medida que se haya comprobado su compatibilidad con el mercado; o, (iii) prorrogar el plazo para la toma de decisión por un periodo adicional de treinta (30) días, en caso sea necesario profundizar en el análisis de la operación.

En línea con lo anterior, es importante mencionar que el artículo 23 del RLASE faculta a la CLC o a la Sala de Defensa de la Competencia del Tribunal del INDECOPI (en segunda instancia) ("Sala") para proponer -en cualquier instancia del procedimiento antes de la decisión finalmodificaciones a la operación de concentración, a efectos de mitigar los efectos negativos que esta pudiera tener en el mercado o en los mercados relacionados.

En caso las partes que intervienen en la operación acepten las recomendaciones de la CLC o de la Sala, según corresponda, la operación sometida al control previo del INDECOPI será aprobada.

\section{iv. Aprobación del acto de concentración}

El solo hecho que la operación notificada constituya un acto de concentración y que supere los umbrales previstos en el segundo párrafo del artículo 3 de la LASE no implica que la operación sometida al control previo del INDECOPI sea ilegal. Por el contrario, el procedimiento de autorización previa tiene por objeto analizar precisamente el impacto (o los efectos) que la operación notificada pueda tener en los mercados vinculados.

$\mathrm{Al}$ respecto, Alberto Rebaza indica que:

“(...) la Ley se inspira en el principio de rule of reason o <regla de la razón>, según el cual los actos denominados <de concentración económica> no se prohíben por sí mismos, sino que se establece que dicho actos estarán sujetos a una autorización que será otorgada dependiendo de los efectos que vaya a generar sobre la libre competencia"13.

13 REBAZA T, Alberto. El control de adquisiciones y fusiones en la nueva ley antimonopolio del sector eléctrico: una raya más al tigre del intervencionismo. THEMIS. N 36. P. 92. 
A partir de lo anterior, es absolutamente posible que un acto de concentración que exceda los umbrales previstos en la LASE sea autorizado por el INDECOPI. En esa línea, el literal b) del artículo 24 del RLASE indica que la CLC podrá "autorizar la Operación de Concentración, en los casos que se compruebe que la operación notificada, pese a encontrarse en el ámbito de aplicación de la Ley, no plantea serias dudas en cuanto a su compatibilidad con el mercado". En otras palabras, los actos de concentración que sean compatibles con el mercado podrán ser autorizados por el INDECOPI.

A efectos de analizar la compatibilidad del acto de concentración con el mercado, la CLC deberá observar lo dispuesto por el artículo 19 del RLASE. De manera específica, la referida norma establece que la CLC debe evaluar si el acto de concentración tiene por objeto disminuir, dañar o impedir la competencia y la libre concurrencia en los mercados de generación, transmisión o distribución eléctrica o en los mercados relacionados.

Del mismo modo, el referido artículo señala que la CLC deberá evaluar, cuando menos:

"la posición de las empresas participantes en el mercado; la delimitación del mercado relevante; la estructura del mismo; las posibilidades de elección de proveedores, distribuidores y usuarios; la existencia de hecho o de derecho de obstáculos de acceso al mercado; la evolución de la oferta y la demanda; la evolución del progreso técnico o económico; la perspectiva de integración con otros mercados; y, el efecto de la operación en los distintos mercados relevantes en el corto y largo plazo".

Finalmente, la evaluación realizada por la CLC también deberá considerar, entre otros aspectos, los impactos del acto de concentración que estén vinculados a mejoras en los sistemas de producción y comercialización, la creación de eficiencias, las limitaciones significativas a la competencia, la facilitación de conductas anticompetitivas y la creación de barreras de acceso.

En caso la evaluación realizada por la CLC evidencie la compatibilidad -en base a los criterios señalados líneas arriba- del acto de concentración con el mercado, la referida operación será autorizada por el INDECOPI. Nótese que la autorización del INDECOPI deberá obtenerse de manera previa a la realización de la operación; caso contrario, la CLC estará facultada para imponer sanciones contra los obligados a notificar el acto de concentración e incluso para iniciar las acciones necesarias para dejar sin efecto la operación de concentración.

De conformidad con el artículo 26 del RLASE, el procedimiento de autorización previa del INDECOPI se encuentra sujeto al silencio administrativo negativo. En ese sentido, la solicitud de autorización se entenderá denegada si la CLC no emite pronunciamiento dentro de los treinta (30) días siguientes a la recepción de la documentación y/o de la información complementaria solicitada por la CLC.

Como indicamos en la sección anterior, la CLC se encuentra facultada para ampliar el plazo para la adopción de la decisión por un periodo adicional de treinta (30) días. Dicha ampliación tendrá por objeto profundizar en el análisis de la operación, 
a efectos de determinar su compatibilidad con el mercado. Para tal propósito, la CLC podrá solicitar a los sujetos del procedimiento la presentación de aclaraciones, ampliaciones, explicaciones o precisiones a la información presentada.

\section{v. Establecimiento de condiciones}

En el marco del procedimiento de aprobación previa de las operaciones de concentración en el sector eléctrico, el INDECOPI está facultado para aprobar las referidas operaciones sujetas al cumplimiento de ciertas condiciones.

Así, el artículo 28 del RLASE establece que "La decisión de la Comisión podrá sujetar la autorización al cumplimiento de ciertas condiciones que considere necesarias para evitar que la Operación de Concentración tenga el efecto de disminuir, dañar o impedir la competencia y la libre concurrencia en los mercados de las Actividades o en los mercados relacionados (...)".

Sobre el particular, cabe señalar que las condiciones a ser impuestas por el INDECOPI pueden ser estructurales o conductuales (o de comportamiento). Las condiciones estructurales se refieren a la reasignación de derechos de propiedad, tales como la venta de activos. Por el contrario, las condiciones conductuales están destinadas a restringir los derechos de propiedad y/o la libertad económica, tales como la obligación de abstenerse de participar de las licitaciones convocadas por el Estado o no ejercer el derecho a voto dentro de una asociación ${ }^{14}$.

A efectos de entender en qué consisten las condiciones que pueden ser impuestas por el INDECOPI en este tipo de operaciones, corresponde remitirnos a algunos pronunciamientos realizados por la CLC sobre este punto.

Por un lado, en el marco de la solicitud de autorización previa hecha por Interconexión Eléctrica S.A. E.S.P. ("ISA") para la adquisición de la totalidad de las acciones de Consorcio Transmantaro S.A., la CLC autorizó la referida operación con la condición de que la referida empresa cumpla con las siguientes condiciones ${ }^{15}$ :

a. Las empresas que integran el grupo económico de ISA deben ejercer un único voto en todas las instancias de decisión del COES, a efectos de que las decisiones dentro dicha organización estén orientadas a la operación eficiente del sistema eléctrico y no a intereses particulares; $y$,

b. Que ISA se abstenga de participar en la segunda convocatoria de licitaciones (o equivalentes) para la construcción y/o ampliación de infraestructura de transmisión eléctrica que en primera convocatoria hayan quedado desiertas por razones de insuficiencia técnica y/o económica.

Lo anterior tuvo por objeto evitar que las empresas que pertenecen al mismo

14 Resolución de la Sala Especializada en Defensa de la Competencia 0623-2014/SDC-INDECOPI, Fundamentos No 63-65.

15 Resolución 081-2006-INDECOPI/CLC, Parte Resolutoria. 
grupo económico que ISA adopten conductas estratégicas a su favor durante el desarrollo de los procesos de licitación, así como también incentivar a las referidas empresas a presentar sus mejores ofertas durante los procesos de selección.

Del mismo modo, en la Resolución 012-99-INDECOPI/CLC la CLC autorizó la adquisición de acciones de Enersis S.A. por parte de la Empresa Nacional de Electricidad S.A. de España y de la Empresa Nacional de Electricidad S.A. de Chile, sujeto al cumplimiento de las siguientes condiciones ${ }^{16}$ :

a. Que por lo menos una de las empresas del Grupo Endesa se abstenga de votar en el COES hasta la fecha en que se interconecten el Sistema Interconectado Centro Norte y el Sistema Interconectado Sur. Lo anterior tenía por objeto garantizar que no se altere el despacho de energía al interior del COES; y,

b. Que EDELNOR licite públicamente sus requerimientos de energía entre todos los generadores existentes en la medida que sus contratos celebrados vayan venciendo.

Ahora bien, cabe señalar que la facultad de la CLC para imponer condiciones no puede ser ejercida de manera irracional. Así, en el precedente de observancia obligatoria contenido en la Resolución de la Sala Especializada en Defensa de la Competencia 0623-2014/SDC-INDECOPI se indicó lo siguiente:

“(i) En el caso se sujete la aprobación de una operación de concentración empresarial al cumplimiento de una condición de conducta, debe entenderse que dicha restricción deberá estar asociada a un horizonte temporal, luego del cual la autoridad deberá revisar las características y el entorno competitivo del mercado, a efectos de determinar si resulta pertinente o no mantener la restricción impuesta.

(ii) Ello, sin perjuicio de que, en aplicación del procedimiento de revocación referido en la Ley 27444, las empresas puedan solicitar cuando lo estimen pertinente, la revocación de las condiciones impuestas, debiendo para tal efecto identificar el cambio de circunstancias que se habría producido en el mercado eléctrico y que ameritaría el levantamiento de las condiciones establecidas válidamente en su oportunidad"17.

A partir de lo anterior, resulta evidente que la imposición de condiciones responde a un objetivo específico: proteger la competitividad del mercado. Es por esta razón que, tal como ha señalado la Sala, las referidas condiciones se encuentran sujetas a un horizonte temporal. Evidentemente, las condiciones impuestas por la CLC o por la Sala carecerán de objeto cuando los efectos del acto de concentración en el mercado hayan sido mitigados.

Finalmente, la Sala apunta a que los administrados podrán solicitar la revocación

16 Resolución 012-99/CLC-INDECOPI, Parte Resolutoria.

17 Resolución de la Sala Especializada en Defensa de la Competencia 0623-2014/SDC-INDECOPI, Fundamento $\mathrm{N}^{\mathrm{o}} 237$. 
de las condiciones impuestas en aplicación del artículo 212 del Texto Único Ordenado de la Ley del Procedimiento Administrativo General. Para ello, se deberá acreditar el cambio de las circunstancias que motivaron la imposición de la condición.

En nuestra opinión, el hecho de que las condiciones impuestas por la CLC o por la Sala estén sujetas a un horizonte temporal y que puedan ser revocadas a solicitud de los administrados es concordante con el principio de razonabilidad. En esa línea, no sería razonable mantener vigente una medida que ya no tiene por objeto proteger el mercado.

\section{vi. Imposición de sanciones}

El INDECOPI no solo se encuentra facultado para aprobar los actos de concentración en el sector eléctrico, sino que también puede imponer sanciones ante el incumplimiento de las disposiciones de la LASE y del RLASE. Al respecto, el artículo 6 de la LASE señala lo siguiente:

"La Comisión de Libre Competencia del INDECOPI podrá imponer a las personas o empresas a que se refiere el Artículo 4 de la presente Ley, multas por un importe no mayor a 500 UIT cuando: omitan la presentación de la solicitud de autorización de un acto de concentración antes de ser efectuado, suministren datos inexactos en la solicitud presentada o en respuesta a los requerimientos de la Comisión, o no proporcionen la información dentro de los plazos establecidos.

Sin perjuicio de lo señalado en el párrafo precedente, la Comisión podrá importar multas de hasta el $10 \%$ de las ventas o ingresos brutos percibidos por las empresas que desarrollan alguna actividad eléctrica en el territorio nacional, involucradas directa o indirectamente en la concentración -en los términos establecidos en el Artículo 3 de la presente Ley-, correspondientes al año inmediato anterior a la decisión de la Comisión, a las personas o empresas a que se refiere el Artículo 4 de la misma, que: realicen el acto de concentración omitiendo solicitar su autorización previa o lo lleven a cabo luego de presentada la solicitud pero antes de la decisión de la Comisión o del Tribunal, realicen un acto de concentración declarado incompatible por tener como efecto el disminuir, dañar o impedir la competencia y la libre concurrencia mediante decisión de la Comisión o no cumplan con las medidas ordenadas mediante decisión adoptada por la Comisión".

A manera de ejemplo, en la Resolución 012-99-INDECOPI/CLC la CLC impuso a las empresas Eléctrica Cabo Blanco S.A., Generalima S.A. e Inversiones Distrilima S.A. una multa equivalente a 150 UIT por haber notificado el acto de concentración (adquisición de acciones de ENDESA por parte de ENERSIS) luego de su realización. Del mismo modo, en la Resolución de la Sala Especializada en Defensa de la Competencia 0794-2011/SC1-INDECOPI la Sala confirmó la sanción de 100 UIT impuesta a Enel S.p.A por haber realizado un acto de concentración luego de 
su notificación pero antes de la decisión de la CLC18.

En ambos casos, el INDECOPI sancionó el incumplimiento a la obligación de notificar eI acto de concentración antes de su ocurrencia, toda vez que, de lo contrario, se estaría solicitando la convalidación (y no la aprobación previa) del acto $^{19}$.

Sin perjuicio de lo anterior, cabe señalar que, de conformidad con el artículo 7 de la LASE, el INDECOPI se encuentra facultado para iniciar las acciones que resulten necesarias -incluyendo el inicio de acciones judiciales- para dejar sin efecto los actos de concentración realizados sin su autorización. En esa línea, el referido artículo señala que las acciones que podrán ser realizadas por el INDECOPI incluyen, entre otras, "(...) la venta de los activos productivos o las acciones, la declaración de nulidad del acto de concentración por vulnerar normas de orden público (...)".

Como se puede apreciar, el INDECOPI cuenta con las herramientas necesarias para garantizar el cumplimiento de la LASE y del RLASE, estando incluso facultada para dejar sin efecto aquellos actos de concentración que hayan sido realizados sin contar con su autorización.

\section{III. ¿Es necesario que exista un control de concentraciones en el sector eléctrico?}

Hasta este punto hemos comentado las principales características del control de concentraciones en el sector eléctrico. Ahora corresponde analizar la conveniencia de que el referido mecanismo de control permanezca vigente $\mathrm{o}$, incluso, se amplíe a todas las industrias conforme ha sido desarrollado en una norma aprobada por el Congreso disuelto, pero aún no publicada.

Como señalamos al inicio del presente artículo, el referido mecanismo de control tuvo como principal objetivo dotar al Perú de una mayor seguridad energética, considerando que hacia finales de los años noventa el mercado eléctrico estaba compuesto por pocos actores. Sin embargo, estas circunstancias han cambiado.

Pues bien, hoy en día existen un gran número de actores que desarrollan actividades de generación, transmisión y distribución a nivel nacional, hecho que torna poco probable que un solo agente económico pueda decidir o impactar sustancialmente la política energética del país.

18 Si bien la Sala confirmó la sanción impuesta por la CLC mediante Resolución 001-2010/CLCINDECOPI, la Sala revocó la decisión en el extremo que fija la multa en 1000 UIT, por considerar que la referida instancia administrativa motivó insuficientemente las razones por las que las que dicha sanción se ajusta al Principio de Razonabilidad.

19 Al respecto, la CLC ha indicado que "La característica ex-ante del actuar de la autoridad de competencia, en lo que al control de concentraciones se refiere, subyace a toda norma, y se basa en la importancia de ejercer un control previo al acto de concentración, teniendo en cuenta que una vez realizado el éste, es mucho más difícil y costos, e incluso hasta podría ser imposible, revertir sus efectos. Aquí reside una de las principales ventajas del control ex-ante de estructuras". Ver Resolución 001-2010/CLC-INDECOPI, Fundamento 53. 
Por si esto fuera poco, el sector eléctrico en el Perú se encuentra altamente regulado, situación que reduce aún más la posibilidad de que un solo agente con posición dominante (o incluso monopólica) pueda incidir de manera significativa en las condiciones del mercado. Siendo ello así, ¿cuál es la utilidad de que se mantenga el control de concentraciones en un sector altamente regulado? Ninguna.

Al respecto, Sergio Salinas indica lo siguiente:

“En principio, si es que este sistema funciona adecuadamente sería poco probable la posibilidad de prácticas anticompetitivas en el mercado. ¿Cómo podrían dos generadores ponerse de acuerdo para perjudicar a otro competidor si el acceso es determinado por un ente distinto como el COES, $\mathrm{y}$ en base a los propios costos que los generadores proporcionan? (...)"20.

Por otro lado, el control de concentraciones en el sector eléctrico tampoco pareciera tener sustento desde un punto de vista práctico. A la fecha, el INDECOPI no ha rechazado ni un solo acto de concentración y ha supeditado la realización de las referidas operaciones al cumplimiento de condiciones específicas únicamente en dos oportunidades.

Lo anterior no hace más que evidenciar que el referido mecanismo de control es innecesario, toda vez que, como el propio INDECOPI ha podido constatar, la mayoría de actos de concentración no genera un impacto negativo en el mercado. Por tal motivo, el control de concentraciones, más allá de proteger el mercado, ocasiona un incremento en los costos de transacción vinculados a las inversiones en materia energética.

A modo de ejemplo, el procedimiento de aprobación previa se encuentra sujeto al pago de una tasa administrativa equivalente al $0.1 \%$ del valor total de la operación hasta un límite de 50 Unidades Impositivas Tributarias (tope fácilmente alcanzable si consideramos la magnitud de las inversiones en materia energética). Como se puede apreciar, el mecanismo de control de concentraciones cuesta tiempo y dinero 21.

Otro de los cuestionamientos al mecanismo de control de concentraciones tiene que ver con el hecho de que busca prevenir conductas a futuro. Así, la eventual prohibición de una operación de concentración tiene por objeto evitar la realización de conductas anticompetitivas por parte de los agentes económicos. Sin embargo, resulta evidente que no se puede predecir la manera en que un agente económico actuará en el futuro, siendo absolutamente posible que el agente

20 SALINAS RIVAS, Sergio. La Ley antimonopolio en el sector eléctrico ¿sobreregulando el mercado? En: Ius et Veritas. N ${ }^{0}$ 33. Pp. 156-157.

21 Sobre este punto, Eduardo Quintana señala que “(..) el control de concentraciones ha demostrado pocos resultados efectivos, es decir, pocas concentraciones de las que se debe proteger al mercado, y sin embargo resulta un sistema sumamente costoso para el Estado, para las empresas y para la sociedad en su conjunto por las equivocaciones que ha tenido (...)". En: QUINTANA SÁNCHEZ, Eduardo. ¿Rezando entre tinieblas?: El credo del control de concentraciones empresariales. En: THEMIS. Nº 39. P. 235. 
económico desarrolle sus actividades sin trasgredir las normas de competencia.

Finalmente, se puede sostener que la incorrecta aplicación del mecanismo de control previsto en la LASE podría generar ineficiencias en el mercado. Como bien indica Alberto Rebaza:

"Las restricciones contenidas en la Ley devienen en ineficientes ya que pretenden excluir a las empresas que, debido a su economía de escala, capacidad de inversión, conocimiento tecnológico, fuentes propias de financiamiento, entre otros, pueden ofrecer un mayor precio por las empresas a privatizarse y un mejor servicio a los consumidores finales a cambio de un menor precio" 22 .

En esa línea, no se debería restringir el aprovechamiento de las economías a escala sino que, por el contrario, el INDECOPI debería llevar a cabo una eficiente labor de fiscalización que garantice el cumplimiento de las disposiciones del Decreto Legislativo 1034, Ley de Represión de Conductas Anticompetitivas. A nuestro parecer, el Perú ya cuenta con mecanismos suficientes para prevenir el abuso de posiciones de dominio, no siendo necesario restringir -innecesariamente- la libertad de empresa de los agentes económicos que intervienen en el sector eléctrico.

\section{Conclusiones}

A partir de lo anterior, es posible concluir lo siguiente:

i. El control previo de concentraciones tuvo por objeto dotar al Perú de una mayor seguridad energética; esto es, prevenir que un solo agente económico pueda incidir significativamente en la política energética del país. Sin embargo, hoy en día, el sector eléctrico cuenta con un gran número de participantes, hecho que torna el control de concentraciones en innecesario.

ii. El sector eléctrico se encuentra altamente regulado, reduciéndose aún más la posibilidad de que los agentes económicos que participan en el referido mercado realicen conductas anticompetitivas. Por tal motivo, el control de concentraciones no constituye un instrumento necesario para garantizar el adecuado funcionamiento del mercado.

iii. En la práctica, el INDECOPI ha autorizado todas las operaciones de concentración que le han sido notificadas. Esto último demuestra que, por lo general, las operaciones de concentración no tienen impactos negativos en el mercado. De tal modo, resulta ineficiente obligar a las empresas del sector eléctrico a pasar por un control de concentraciones que, más allá de generar un impacto real en el mercado, incrementa los costos de transacción.

iv. El control de concentraciones busca evitar que los agentes económicos que cuenten con posición de dominio en el mercado realicen conductas

22 REBAZA T, Alberto. El control de adquisiciones y fusiones en la nueva ley antimonopolio del sector eléctrico: una raya más al tigre del intervencionismo. En: THEMIS. Nº 36. P. 101. 
anticompetitivas. Sin embargo, no es razonable que se implemente un mecanismo de control que se fundamenta en hechos que aún no han ocurrido y que no se pueden anticipar. En todo caso, el Perú cuenta con instrumentos adecuados para sancionar a quienes actúen de forma contraria a la libre competencia de manera posterior.

v. El control de concentraciones restringe la posibilidad de aprovechar las economías de escala. En un sector tan especializado como el eléctrico, resulta imprescindible que los actores que vienen operando en el mercado tengan la posibilidad de expandirse. 